\title{
Does China's OFDI Successfully Promote Environmental Technology Innovation?
}

\author{
Bing Han \\ College of Humanity and Law, Shandong University of Science and Technology, Qingdao 266590, China \\ Correspondence should be addressed to Bing Han; bhan.heu@gmail.com
}

Received 30 June 2020; Revised 21 September 2020; Accepted 4 March 2021; Published 13 March 2021

Academic Editor: Zhile Yang

Copyright (c) 2021 Bing Han. This is an open access article distributed under the Creative Commons Attribution License, which permits unrestricted use, distribution, and reproduction in any medium, provided the original work is properly cited.

\begin{abstract}
Environmental technology innovation is a crucial measure of the quality of China's economic development and sustainable environmental protection. Based on the 2009-2017 provincial panel data from China, this article used the modified projection pursuit model to measure the environmental technology innovation capabilities of various regions. Moreover, this article empirically investigates the threshold effect of outward foreign direct investment on China's environmental technology innovation under different intellectual property protection levels. The results are as follows. First, the environmental technology innovation capabilities of China's regions vary significantly, showing an "east-middle-west" gradient decline trend similar to levels of economic development. Second, outward foreign direct investment has a significant reverse environmental technology innovation effect, but this effect has complex nonlinear characteristics. Third, in the process of outward foreign direct investment affecting environmental technology innovation, intellectual property protection has a significant double threshold effect. As the level of intellectual property protection continues to cross the threshold value, the effect direction of outward foreign direct investment on environmental technology innovation undergoes a sudden change from inhibition to promotion. However, when intellectual property protection is too high, the promotion effect is relatively limited. This paper provides some reference points and insights that should aid in establishing a scientific intellectual property protection system and raising the level of environmental technology innovation.
\end{abstract}

\section{Introduction}

The continuous growth of China's industrial economy has accelerated the emergence of environmental crises, including the energy crisis, the ecological crisis, and the climate change crisis. At present, China's GDP accounts for more than $16 \%$ of global GDP, and its economic growth contributes about $30 \%$ to world economic growth. However, China has also become the world's largest resource consumer and carbon dioxide emitter, and it should shoulder more responsibility for resource protection and ecological restoration. Due to China's huge population base, the industry will remain the lynchpin of the national economy in the short term. Therefore, China and other developing countries must seek to bolster environmental technology innovation (ETI) to promote intensive economic development.
The steady progress of economic globalization and China's increasing openness to outside world have facilitated significant achievements in China's "go global" strategy. More and more domestic enterprises have turned their sights abroad and invested in other countries. Outward foreign direct investment (OFDI) is among the most effective ways for home countries to obtain the advanced technology, scarce resources of host countries, expand the international market, and improve the operating efficiency of enterprises. Investment is closely related to institutional environments, and intellectual property protection (IPP) is shared among the most critical institutional settings for enterprises to conduct OFDI $[1,2]$. The deepening of the economic globalization has made the role of intellectual property increasingly crucial in industrial competition, and the intellectual property system has become an endogenous variable of transnational corporations' direct investment. 
Although scholars have extensively analyzed the reverse spillover effect of China's OFDI, most have merely examined OFDI's unilateral impact on technological innovation or environmental pollution. At its core, China's innovationdriven development strategy suggests that China needs to enhance its ETI capabilities by embracing a more sustainable development-oriented approach [3]. At the same time, because of the influence of IPP on the OFDI reverse spillover effect process, this article adopts a regional perspective based on the real IPP levels in each region. It conducts an in-depth study of the impact of OFDI on ETI, intending to answer the following questions. What are the ETI levels in various regions of China, and is there regional heterogeneity? In the context of the IPP, is there a nonlinear relationship between OFDI and ETI? From a regional perspective, how can China more effectively match OFDI and IPP and thereby improve its ETI level? The study of these issues has great practical significance for the sustainable development of the Chinese economy.

\section{Literature Review and Research Hypothesis}

The reverse innovation spillover effect of OFDI has been the focus of past research and received attention from governments and academia in various countries for more than a decade. The impacts of OFDI on technological innovation capabilities can be divided into three rough categories. First, some scholars believe that OFDI has a significant technology spillover effect. Li [4] and Sha [5] identified OFDI as one of the main channels for international technology spillovers, claiming that it plays a decisive role in promoting China's technological innovation capabilities. Chang et al. [6] analyzed multinational panel data and showed that OFDI could significantly promote home country technology innovation. Meanwhile, $\mathrm{Wu}$ and Qiu [7] empirically analyzed the positive impact of OFDI on home country technology innovation from the perspective of $R \& D$ investment and $R \& D$ output. Second, some scholars have pointed out that OFDI has not produced a significant reverse innovation spillover and even inhibited the improvement of home countries' innovation capacities. In an analysis of 16 OECD countries, Lee [8] found that the technology spillover effect of OFDI was not significant. Bitzer and Kerekes [9] used the standard Cobb-Douglas production function method to show that OFDI does not produce substantial reverse innovation spillover effects. Using panel cointegration technology, Herzer and Direk [10] analyzed panel data from 33 developing countries and validated it, further confirming the conclusions of Bitzer and Kerekes [9]. Similarly, Xie et al. [11] pointed out that OFDI only plays a specific role in domestic imitation and innovation abilities but has an inhibitory effect on China's overall innovation ability. Li and $\mathrm{Yu}$ [12] used an econometric model to examine the relationship between corporate innovation efficiency and OFDI empirically. They found that OFDI promotes innovation input but also leads to imbalances between innovation input and innovation output. In the end, their analysis showed that OFDI can lead enterprises to generate relatively insufficient innovation outputs and that it will generally inhibit the improvement of corporate innovation efficiency. Third, some scholars believe that OFDI's innovation spillover effect is not absolute. Cohen and Levinthal [13] proposed that due to the absorptive capacity of different regions, OFDI's reverse innovation spillover effect varies by region. Using the generalized matrix estimation method, Kan [14] conducted an empirical analysis of industrial enterprises panel data and contended that effectively utilizing the OFDI's technological innovation effect requires market-oriented reforms, the creation of an excellent institutional environment, and eventually the formation of a technological innovation system based on industry-university-research collaboration. Zhang [15] used 2003-2015 interprovincial panel data from China to construct a spatial threshold regression model confirming that environmental regulation has dramatically affected OFDI's reverse technology spillover effect.

Research regarding the impact of OFDI on environmental pollution is still in its infancy. First, some scholars believe that OFDI can effectively improve local ecological problems. For example, by analyzing the OFDI behavior of highly polluting companies, Eskeland and Harrison [16] proposed that OFDI is conducive to improving the environmental performance of the home and host countries through pollution avoidance effects. Yang and Liu [17] studied OFDI's effect on home country carbon emissions in Japan and found that OFDI can effectively reduce carbon emissions. Ouyang et al. [18] used the panel space lag model to analyze listed Chinese companies' OFDI data from 2005 to 2016 and found that the OFDI effectively improves regional environmental pollution. Second, some scholars point out that the impact of OFDI on the environment is relative. Using simultaneous equations and scenario simulations, Zhou and Pang [19] empirically analyzed the home country's environmental effects of China's OFDI. They concluded that OFDI has both positive and negative impacts on the home country environment. Han et al. [20] used cointegration analysis, the error correction model, and the impulse response function to analyze a two-way FDI and pollutant emission time series in China from 1995 to 2015 and empirically test the relationship between FDI, OFDI, and the environment. Furthermore, they proposed that in the short term, OFDI has an inhibitory effect on the ecological environment, but in the long term, OFDI can promote environmental improvement. Third, some scholars believe that OFDI will hurt the environment. Liu and Li [21] used the panel data of 30 provinces in China from 2004 to 2013 to conduct an empirical analysis of the carbon emission effect of China's foreign direct investment in the home country. They found that OFDI increases China's carbon emissions and negatively affects the environment of the home country. Similarly, by constructing dynamic and static panel models, Wang and Zhu [22] demonstrated that OFDI has not played a significant role in improving China's environment.

We found that the existing literature mostly focuses on the impact of OFDI on either technological innovation or environmental pollution. However, in the context of the new economic normal, the core of China's promotion of highquality economic development lies in realizing technological 
innovation under the premise of ensuring ecological performance, rather than merely enhancing innovation capabilities or reducing the environmental pollution. More importantly, as an important driving force for intensive economic development, environmental technology innovation can effectively promote the transformation of China's economic development mode and realize an innovationdriven intensive economic development model [23]. Therefore, this article contends that exploring whether China's OFDI has effectively promoted environmental technology innovation performance is crucial. In connection with the above theory, this paper's analysis of OFDI's reverse environmental technology innovation spillover showed that after China acceded to the World Trade Organization, the opening level of Chinese trade has continued to grow. The amount of foreign investment has continued to increase [24]. At the same time, China's environmental technology innovation capabilities have been significantly enhanced, which has begun transforming from a traditional manufacturing country into a smart manufacturing power, and its level of sustainable development is continuously improving [25]. This leads us to wonder whether efforts to improve environmental technology innovation capabilities benefit from the increasing OFDI level. Based on the above analysis, this study proposes the following hypothesis.

Hypothesis 1. When other conditions are unchanged, the higher the OFDI level, the stronger the environmental technology innovation ability.

Scholars pay special attention to intellectual property as a significant institutional environment factor when analyzing OFDI's reverse spillover effect. In their empirical analysis, Li and Zhao [26] found that IPP rights positively regulate OFDI's reverse industrial upgrading effect of OFDI and make a significant spatial difference. In their analysis of OFDI's reverse employment effect, Han et al. [27] showed that the employment effect could be effectively exerted only at a reasonable level of IPP. At the same time, they found that the level of urbanization and trade openness also has corresponding threshold functions. Meanwhile, in an analysis of multinational samples, Fang et al. [28] examined the impact of IPP on the location selection and investment scale of OFDI. They found that market size and political environment are also essential factors of OFDI. After conducting a field inspection of the IPP systems in 23 countries, Papageorgiadis et al. [29] analyzed the differences in the level of China's foreign direct investment. They found that Chinese enterprises are more likely to invest in countries with weak IPP systems.

Nevertheless, the question remains: is a higher intensity of intellectual property protection better? Ezzeddine and Hammami [30] proposed that the relationship between intellectual property protection and technological progress in emerging economies does not follow a simple linear trajectory, but an "inverted U-shape." This article contends that the protection of intellectual property rights will give property owners a certain degree of monopoly power. To maintain their advantages and maximize their interests, technology monopolies will make full use of intellectual property rights to prevent technology leakage, leading to increased costs for other technology users. Therefore, strengthening intellectual property protection reduces the risk of technology transfer. However, strengthened protection will restrict free competition and increase the cost of technology for benefit diffusion in developing countries, making technology transfer and technology imitation very expensive, which is not conducive to the spillover of advanced technologies, especially high-end technologies cleaner production. Furthermore, OFDI cannot effectively promote the improvement of environmental technology innovation capabilities. On the other hand, this paper also contends that when intellectual property protection levels are too low in the home country, the investment council will worry about the risk of the theft of its intellectual achievements and therefore transfer some products with lower technical content to it. This means the home country will be unable to obtain technology spillovers through foreign investment.

Based on the above analysis, this article argues that intellectual property protection has a certain impact on OFDI's reverse environmental technology innovation spillover. While the impact is nonlinear, there is an optimal interval. Too strong or too weak intellectual property protection cannot effectively promote OFDI's reverse environmental technology innovation spillover. Therefore, this paper proposes the following second hypothesis.

Hypothesis 2. When other conditions are unchanged and when the intensity of intellectual property protection is within a specific range, OFDI can effectively promote the reverse environmental technology innovation spillover in the home country.

\section{Calculation and Analysis of ETI Level}

3.1. Calculation of ETI Level. Projection pursuit is a statistical method for processing and analyzing high-dimensional data. Its primary way is to reduce the dimensionality of high-dimensional data by optimizing the projection direction. The low-dimensional data found can reflect the structural characteristics of high-dimensional data and through the low-dimensional data to carry on the analysis and the processing to the high-dimensional data [31]. Drawing on Wang et al.'s [32] point of view, this paper uses the technological innovation capability of a unit of energy consumption to characterize ETI level. Among them, technological innovation includes two dimensions of knowledge benefits and economic benefits: knowledge benefits are expressed by the number of valid invention patents of industrial enterprises above the designated size in each region; meanwhile, the economic benefits are expressed by the new product development funds and new product sales income from industrial enterprises above the designated size in each region, dimension reduction of the three indicators of sales revenue per unit energy consumption of new products, the new product development expenditures per unit energy consumption, and the number of valid invention patents per unit energy consumption in 30 regions 
from 2009 to 2017 . The specific calculation method is as follows:

\subsubsection{Constructing the ETI Projection Values}

$$
Z(i)=\sum_{j=1}^{p} X(i, j) a(j),
$$

where $a(j)$ represents the projection value of the $j$-th variable in 30 regions, $j=1,2,3$, and $X(i, j)$ represents the value of the $j$ - th index of the $i$ - th evaluation target.

\subsubsection{Constructing the Projection Index Function}

$$
Q(a)=S_{z} D_{z}
$$

where $S_{z}$ is the standard deviation of $Z(i)$ and $D_{z}$ is the local density of $Z(i)$.

\subsubsection{The Optimized Projection Index Function. When the} projection index function takes the maximum value, $a$ is the best projection direction corresponding to $Q(a)$; construct $\left\{a(j)_{t} \mid j=1,2,3 ; t=1,2, \ldots, 9\right\}$ as a complex nonlinear optimization function for the optimization variable. Optimize the best projection direction of the projection function and solve the maximum function of the projection function; that is, $\left\{\begin{array}{l}\max Q\left(a_{t}\right)=S_{z} D_{z} \\ \text { s.t. } \sum_{j=1}^{3} a^{2}(j)_{t}=1\end{array}\right.$.

3.1.4. Calculation of ETI Level. Substitute the best projection direction into the projection value function to generate the annual ETI index; the result is the ETI index of each region from 2009 to 2017.

3.2. Analysis of ETI Level. Overall, the average value of China's ETI increased from 0.2036 to 0.4687 between 2009 and 2017, which indicates that China's awareness of ETI and its related capabilities are gradually increasing (Figure 1). However, because of regional differences in local policies, economic development levels, industrial structures, and human resources, significant gaps in ETI capabilities exist in various regions, and ETI levels in the different areas of China urgently need to be improved.

Specifically, there are significant regional differences in China's environmental technology innovation level, showing a decreasing trend of "east-middle-west "similar to the level of economic development. In terms of the ETI level, the top five provinces are Guangdong, Jiangsu, Zhejiang, Shanghai, and Beijing. These provinces are concentrated in the developed areas of eastern China. In 2017, the GDPs of these five regions accounted for more than $30 \%$ of the country's GDP and led to China's overall economic development. As Figure 1 shows, Guangdong province became the country's top province in ETI capacity between 2013 and 2017. Over the years, Guangdong has continued to improve its ecological environment by implementing top-level green development designs, successfully introducing regulations such as the "Thirteenth Five-Year Plan" for Environmental Protection in Guangdong Province and the Action Plan for Air Pollution Prevention and Control in Guangdong Province, establishing the strictest environmental protection policies, actively eliminating backward production capacities, forcing enterprises to transform and upgrade, and strengthening the management of energy-saving, bolstering emission-reduction and carbon-restrictive indicators. Guangdong also leads the country in the practice of green development and green living concepts. It has established special funds for local ecological protection compensation, implemented an environmental protection performance evaluation system, set up comprehensive resource and environmental law enforcement departments, created the ecological environment index, etc. The blue sky, green water, and high quality are being developed into Guangdong's bright business cards.

The provinces with the lowest levels of ETI in China, such as Qinghai, Xinjiang, and Ningxia, are mainly concentrated in western China. Abundant natural resources have fueled development in western China, and the area's economy has increased. However, backward infrastructure and weak technology have made environmental pollution worse, and ETI levels have remained low during the process of economic development.

The fact that the overall level of ETI in northeast China (Liaoning, Jilin, and Heilongjiang) is weak and has not significantly improved in recent years warrants mention. As northeast China is an essential old industrial base, with a strong industrial foundation and heavy industry as its mainstay, its economic development still relies heavily upon factor inputs. Although some achievements have been made in pollution control, the predominant economic development methods and low technological innovation capabilities have prevented full environmental pollution.

\section{Empirical Model and Variables}

4.1. Construction of Panel Threshold Model. Foreign technology transfer and independent $R \& D$ are the primary sources of technological innovation. Reliable IPP can promote independent $\mathrm{R} \& \mathrm{D}$ and direct investment of foreign capital, thereby increasing foreign technology investment in the country; however, the proportion of technology spillovers will decrease accordingly. Weak IPP will reduce independent R\&D and direct foreign capital investment, but the dimension of technology spillovers will increase, eventually rising technological innovation. Therefore, this article uses the IPP index as the threshold variable and tries to study nonlinear threshold effects between IPP, OFDI, and environmental technological innovation.

Different degrees of intellectual property rights have different effects on OFDI's environmental technology spillovers. Therefore, the intellectual property system plays an indispensable role in the process of innovation-driven development in China. When an intellectual property reaches a certain threshold, it will cause another economic parameter to affect other forms of development suddenly. The threshold at the root of this phenomenon is called a nonlinear "structural change" problem. Following this logic, the samples on both sides of the critical value are different and must be tested separately. To 


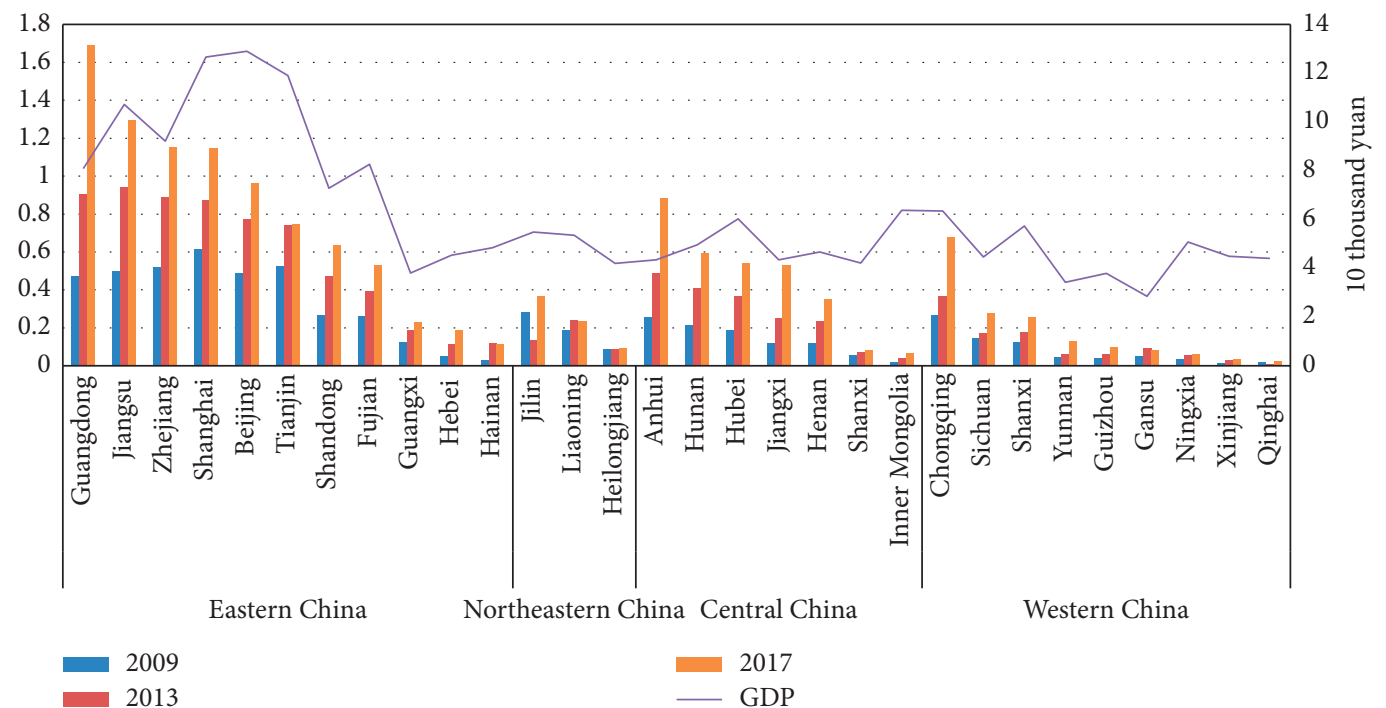

Figure 1: China's level of ETI (2009, 2013, and 2017) and economic development level (2017).

avoid the bias of artificially dividing the dial of the intellectual property protection interval, Hansen [33] first proposed a panel threshold regression model. His nonlinear threshold panel regression can endogenously divide the interval of intellectual property protection strength according to the characteristics of the data itself and effectively identify the nonlinear threshold characteristics caused by the structural mutation of the economic system. Besides, it also has positive characteristics for and effects on analysis, such as the fixation of general panel data models. Therefore, this paper uses the threshold model to study the influence mechanism of OFDI on environmental technology innovation in different ranges of intellectual property protection intensity.

(1) Single threshold panel model with OFDI as the explanatory variable:

$$
\begin{aligned}
\mathrm{ETI}_{i t}= & \theta+\alpha_{1} \mathrm{City}_{i t}+\alpha_{2} \mathrm{Human}_{i t} \\
& +\alpha_{3} \mathrm{LCED}_{i t}+\alpha_{4} \mathrm{ICT}_{i t} \\
& +\beta_{1} \mathrm{OFDI}_{i t} I\left(\mathrm{IPP}_{i t} \leq \eta\right)+\beta_{2} \mathrm{OFDI}_{i t} I\left(\mathrm{IPP}_{i t}>\eta\right) \\
& +u_{i}+\partial_{t}+\varepsilon_{i t} .
\end{aligned}
$$

(2) Double threshold panel model with OFDI as the explanatory variable:

$$
\begin{aligned}
\text { ETI }_{i t}= & \theta+\alpha_{1} \text { City }_{i t}+\alpha_{2} \text { Human }_{i t}+\alpha_{3} \mathrm{LCED}_{i t} \\
& +\alpha_{4} \mathrm{ICT}_{i t}+\beta_{1} \mathrm{OFDI}_{i t} I\left(\mathrm{IPP}_{i t} \leq \eta_{1}\right) \\
& +\beta_{2} \mathrm{OFDI}_{i t} I\left(\eta_{1}<\mathrm{IPP}_{i t} \leq \eta_{2}\right) \\
& +\beta_{3} \mathrm{OFDI}_{i t} I\left(\mathrm{IPP}_{i t}>\eta_{2}\right)+u_{i}+\partial_{t}+\varepsilon_{i t},
\end{aligned}
$$

where $i$ and $t$ represent the province and the year, respectively, ETI stands for environment technology innovation capability, City stands for the level of urbanization, Human stands for human capital level, LCED stands for low-carbon economic development level, ICT stands for information and communication technology application level, OFDI stands for outward foreign direct investment per unit of output, $I(\bullet)$ is an indicator function, $\eta$ stands for the threshold variable value, $u_{i}$ stands for the specific effect of the individual, $\partial_{t}$ stands for the specific effect of time, and $\varepsilon_{i t}$ is a random interference term. Meanwhile, the construction of the multiple threshold panel regression models is the same as above and is therefore not repeated here.

The nonlinear panel threshold model requires not only jointly estimating the threshold value and parameters but also testing the correlation of the threshold effect in the following two ways. First, the existence of the threshold effect must be tested by processing the given threshold, the residual square of the least-squares regression, and the minimum parameter estimates, and then using the "bootstrap sampling method" to test the significance of $P$ value. Second, the authenticity of the threshold estimate must be tested. Taking a single threshold test as an example, the null hypothesis $H_{0}: \eta_{1}=\eta_{2}$; likelihood ratio statistics are LR and follow a nonstandard normal distribution.

A threshold value test based on Hansen's formula for calculating the rejection domain, that is, under the condition of significance level IPP, rejects the null hypothesis when LR $>-2 \ln (1-\sqrt{1-I P})$. The test method for multiple thresholds is similar.

\subsection{Variable Description and Processing}

4.2.1. Explained Variable. ETI $\left(\mathrm{ETI}_{i t}\right)$ is calculated by the RAGA-PP model. 
4.2.2. Explanatory Variables. Outward foreign direct investment $\left(\mathrm{OFDI}_{i t}\right)$ : statistics reflecting foreign direct investment are divided into flow data and stock data. OFDI traffic data fluctuates wildly, and the residual value of the previous period may continue to play a role. However, OFDI's stock data can better reflect the benefits and research value of a foreign direct investment in a given region. Therefore, this article adopts the ratio of OFDI stock to the capital stock of the area to measure the OFDI index. To accomplish this, this paper processes OFDI stock data using the perpetual inventory method; the formula is as follows:

$$
K_{t}=K_{t-1}+\frac{\left(I_{t}-D_{t}\right)}{P_{t}},
$$

where $K_{t}$ is the current OFDI stock, $K_{t-1}$ is the previous OFDI capital stock, $I_{t}$ is the total nominal fixed OFDI capital formation of the year, $D_{t}$ is the nominal depreciation of the year, and $P_{t}$ is the fixed asset investment price index of the current year, converted to the constant price level in 2009.

This article uses the following formula to determine the OFDI capital stock for the base period:

$$
K_{0}=\frac{I_{0}}{(\bar{g}+\delta)}
$$

where $\bar{g}$ is the real average annual growth rate of the total fixed OFDI capital formation in each region during the sample period, $K_{0}$ and $I_{0}$ are, respectively, OFDI capital stock and total fixed capital formation in 2009, and $\delta$ is the depreciation rate according to the existing literature [34]; the value is $9.6 \%$.

4.2.3. Threshold Variables. Intellectual property protection $\left(\mathrm{IPP}_{i t}\right)$ : different scholars have used different approaches to measure the level of intellectual property protection. This paper follows Ginarte and Park [35], Park [36], and Wu and Tang [37] in measuring the level of intellectual property protection from two perspectives: administrative enforcement and judicial security. The index of administrative enforcement mainly refers to the rate of patent infringement. The patent infringement rate is the ratio of the total number of accepted patent dispute cases to the total number of patents granted by the province at the end of the year. The percentage of noninfringed patents is one minus the percentage of infringed patents. The effect of IPP is represented by the patent infringement rate. The higher the patent infringement rate, the higher the level of IPP. The indicators of judicial protection level are borrowed from $\mathrm{Xu}$ and Shan [38] and measured by the number of lawyers per 10,000 people in a given area. Countries or regions with five lawyers per 10,000 people are deemed to have high levels of judicial protection. This paper calculates the level of IPP based on the arithmetical average of the patent noninfringement rate and the number of lawyers per 10,000 people.

4.2.4. Control Variables. To minimize the impact of missing related variables on the results, this paper controls other related variables that may affect environmental technology innovation.

City $\left(\right.$ City $\left._{i t}\right)$ : innovative elements such as high-quality talents and capital are concentrated in cities, and knowledge and innovation spillovers have significant effects. Therefore, the level of urbanization has a particular effect on the promotion of environmental technology innovation. This paper uses the ratio of urban population to total population in each region to determine urbanization.

Human capital $\left(\operatorname{Human}_{i t}\right)$ : a low stock of human capital in a country or region will result in a lack of complementary capabilities to absorb or transform foreign advanced technologies, which will inhibit the improvement of domestic innovation capabilities. This paper uses the average years of education of the employed population to measure human capital. Most existing literatures divide population education into five levels, namely, illiterate and semi-illiterate, elementary school, junior high school, high school, junior college, and above. This article believes that, with the continuous popularization of higher education in China and the continuous accumulation of highly educated talent, human capital divisions should be more detailed. The employed population with postgraduate degrees and above should be taken into consideration. This calculation improves the accuracy of the data and can prevent the underestimation of educated human capital. This calculation improves the accuracy of the data and can avoid the underestimation of education human capital.

Low-carbon economic development $\left(\operatorname{LCED}_{i t}\right)$ : the development of a low-carbon economy means that while the economy is growing, the amount of carbon dioxide emissions per unit of gross national product is gradually decreasing, thereby promoting both sustainable economic development and environmental technological innovation and progress. This article uses the carbon emission intensity per person to represent the level of low-carbon economic development.

Information and communication technology $\left(\mathrm{ICT}_{i t}\right)$ : the widespread use of information and communication technology has accelerated the coding of knowledge, which helps enterprises obtain cutting-edge technical knowledge, promoting technological progress, and innovation spillover. This paper uses the number of employees in the information transmission, software, and information technology service industries as a measure of the information and communication technology level.

This article analyzes the Chinese provincial data from 2009 to 2017. The sample lacks data from Tibet, Hong Kong, Macau, and Taiwan; it, therefore, covers the remaining 30 provinces (cities and districts). This paper sourced the data used from the Annual Report of the China IPP Bureau, the China Energy Statistics Yearbook, the China Science and Technology Statistics Yearbook, the China Statistics Yearbook, and the Statistical Analysis Report of China's Lawyer Industry Development. To compensate for missing data, this paper utilizes adjacent data. Meanwhile, to control potential estimation error and heteroscedasticity, this paper treats the related variables with logarithmic processing and a deflator. Table 1 shows a sample descriptive statistical analysis. 
TABLE 1: Variable descriptive statistics.

\begin{tabular}{lccccc}
\hline Variable & Mean & S.D. & Variance & Max & Min \\
\hline ETI & 0.322383 & 0.32013 & 0.1028639 & 1.68718 & 0.001558 \\
OFDI & 0.063974 & 0.090199 & 0.008661 & 0.685878 & 0.000658 \\
IPP & 1.122977 & 0.588053 & 0.3470918 & 5.38485 & 0.650517 \\
City & 0.553337 & 0.1296256 & 1.0168028 & 0.896 & 0.2989 \\
Human & 9.813203 & 1.134509 & 1.287111 & 13.741 & 7.0776 \\
LCED & 12.39874 & 10.97459 & 120.4416 & 59.87074 & 2.784655 \\
ICT & 10.98737 & 0.9660285 & 0.9332111 & 13.55984 & 8.695004 \\
\hline
\end{tabular}

TABLE 2: Test results of threshold significance.

\begin{tabular}{lccccc}
\hline \multirow{2}{*}{ Threshold } & $F$-value & $P$-value & \multicolumn{4}{c}{ Critical value } \\
\hline $\begin{array}{l}\text { Single } \\
\text { threshold }\end{array}$ & $50.1^{*}$ & 0.0633 & 83.678 & 53.2775 & 37.1065 \\
$\begin{array}{l}\text { Double } \\
\text { threshold }\end{array}$ & $45.23^{* *}$ & 0.0067 & 42.7996 & 30.7599 & 22.7573 \\
$\begin{array}{l}\text { Triple } \\
\text { threshold }\end{array}$ & 28.41 & 0.5033 & 92.2770 & 76.3859 & 64.3616 \\
\hline
\end{tabular}

Note. The $P$ - value and the critical value are obtained from 300 bootstrap replications. ${ }^{* *}$, and ${ }^{*}$ denote significant levels at $1 \%, 5 \%$, and $10 \%$, respectively.

TABLE 3: The threshold value and confidence intervals.

\begin{tabular}{lcc}
\hline Model & $\begin{array}{c}\text { Threshold } \\
\text { estimators }\end{array}$ & $\begin{array}{c}95 \% \text { confidence } \\
\text { intervals }\end{array}$ \\
\hline Single threshold & 1.0616 & {$[1.0535,1.0642]$} \\
Double threshold & 1.3551 & {$[1.3134,1.3859]$} \\
\hline
\end{tabular}

\section{Empirical Results and Analysis}

5.1. Empirical Results and Analysis. Using the threshold model and estimation method mentioned above, this paper calculated the model with IPP as the threshold variable. Tables 2 and 3 show the obtained $F$-value, $P$-value, threshold value, critical value, and $95 \%$ confidence interval. As indicated in these results, when IPP is used as the threshold variable, there is a threshold effect between OFDI and ETI. The single threshold is significant at the $10 \%$ level, the $\mathrm{F}$ value is 50.1 , the self-sampling $P$ - value is 0.0633 , the double threshold is significant at the $5 \%$ level, the $\mathrm{F}$ value is 45.23 , the self-sampling $P$ - value is 0.0067 , and the triple threshold is not significant. Following the Hansen threshold theory, this indicates that there is a significant double threshold effect. Since the significance level of the dualthreshold model is significantly higher than that of the single threshold model, and the triple threshold model is not significant, this paper uses the dual-threshold test to conduct empirical analysis.

The double thresholds are 1.0616 and 1.3551, respectively. The $95 \%$ confidence interval corresponding to the single threshold obtained is $[1.0535,1.0642]$, and the second is $[1.3134,1.3859]$. This verifies the authenticity of this model's threshold.

Combined with the likelihood ratio function graph (Figure 2), in this paper's threshold model, the 95\% confidence interval of each threshold estimate is the interval formed by all critical values (corresponding to the dotted line in the figure) at the significance level for all LR values of less than $5 \%$, passing the threshold value authenticity test. Therefore, according to these threshold data, China's regions can be divided into three areas: low IPP (IPP $\leq 1.0616$ ), medium IPP $(1.0616<$ IPP $\leq 1.3551)$, and high IPP (IPP $>1.3551)$. This paper conducts a detailed analysis of the double threshold effect using the threshold model.

As Table 4 shows, the first threshold for IPP is 1.0616, and when the threshold is below this number, the regression coefficient of OFDI on ETI ability is -0.2945 at the $10 \%$ significance level. This shows that when IPP is low, there is a risk that technology will be imitated; that is, it will not provide an excellent technical environment for home countries, and OFDI will inhibit ETI abilities. The second threshold is 1.3551 . When the IPP is between 1.0616 and 1.3551 , the regression coefficient is 1.578 at the $1 \%$ significance level. Thus, the effect of OFDI on ETI changes from inhibition to promotion, indicating that when IPP crosses the first threshold, the direction of OFDI's impact on ETI changes significantly from negative to positive, which reflects the concept of structural mutation in the threshold model theory. However, intellectual property rights continue to strengthen after the second threshold. Consequently, although the regression coefficient is still positive, the effect coefficient reduces to 0.4832 , indicating that the promotion effect of OFDI on ETI weakens in this interval.

Taken together, in the three ranges of IPP, OFDI's role in improving ETI is the most significant in the medium IPP range $(1.1528<\mathrm{IPP} \leq 1.3551)$. Therefore, the medium IPP interval $(1.1528<\mathrm{IPP} \leq 1.3551)$ is the optimal interval for this study. In the process of OFDI's reverse green technological innovation spillover effect, the protection of intellectual property rights is neither as small nor as large as it could be. Instead, there is an optimal interval-as suggested in Park's "optimal IPP interval hypothesis" [29].

Regarding the other forces promoting ETI, the elasticity coefficient of the city for ETI in various regions is 0.9807 at the $5 \%$ level of significance, indicating that urbanization is an essential factor driving the improvement of environmental technology innovation capabilities. Therefore, the government should continue to promote high-level urbanization, strengthen scientific planning, and give full play to the role of urbanization in promoting ETI. However, it warrants mention that when the government increases the urbanization rate, it must not blindly expand the scales of cities and increase urban populations. It must pay attention to the quality of urbanization development and promote sustainable urban development. The elasticity coefficient of LCED is -0.0053 at the $1 \%$ level of significance, which indicates that the development of a low-carbon economy could significantly promote the improvement of environmental technology innovation capabilities. Generally speaking, regions with high levels of low-carbon economic development have more reasonable industrial structures, better ecological environment protections, and more robust environmental technology innovation capabilities. Therefore, while ensuring GDP growth, regional governments 


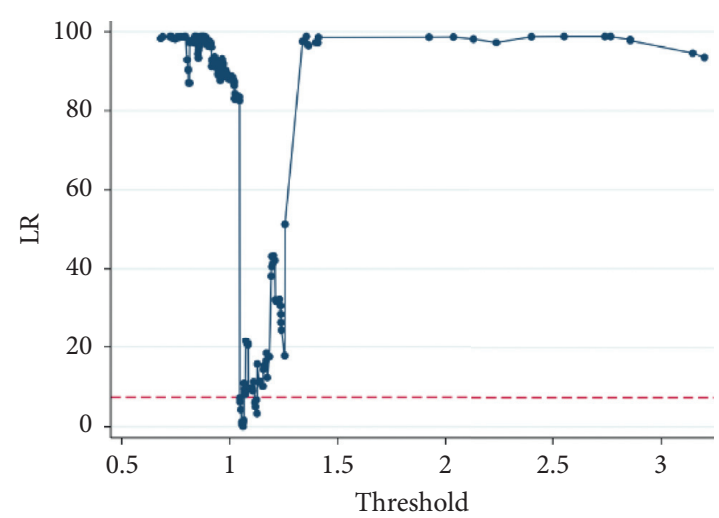

(a)

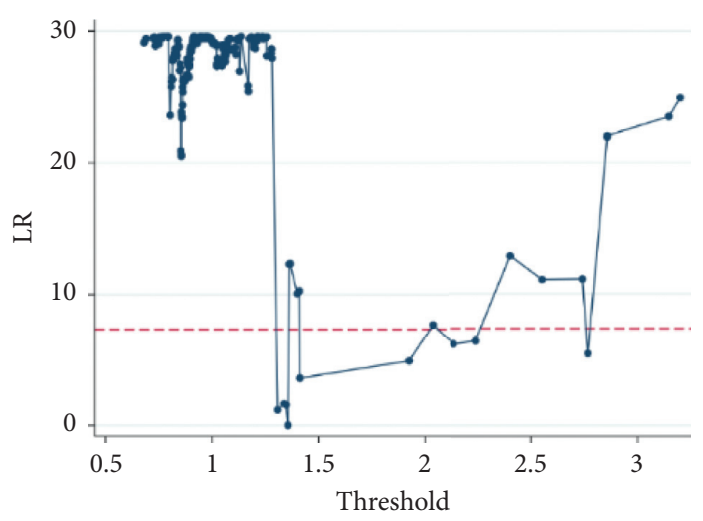

(b)

FIgURE 2: The construction of confidence intervals. (a) The first threshold value. (b) The second threshold value.

TABLE 4: Model parameter estimation result.

\begin{tabular}{lcccccc}
\hline ETI & Coef. & Std. err & $\mathrm{t}$ & $P>|t|$ & $95 \%$ & Conf. interval \\
\hline City & 0.9807 & 0.2871 & 3.42 & 0.001 & 0.4151 & 1.5463 \\
Human & 0.0222 & 0.0177 & 1.25 & 0.213 & -0.0128 & 0.0571 \\
LCED & -0.0053 & 0.0016 & -3.29 & 0.001 & -0.0085 & -0.0021 \\
ICT & 0.1602 & 0.0258 & 6.20 & 0.000 & 0.1093 & 0.2111 \\
OFDI $($ IPP $\leq 1.0616)$ & -0.2945 & 0.1550 & -1.90 & 0.059 & -0.6 & 0.0109 \\
OFDI $(1.0616<$ IPP $\leq 1.3551)$ & 1.5780 & 0.1696 & 9.3 & 0.000 & 1.2437 & 1.9121 \\
OFDI $($ IPP $>1.3551)$ & 0.4832 & 0.1072 & 4.51 & 0.000 & 0.272 & 0.6945 \\
Cons & -2.154 & 0.2236 & -9.63 & 0.000 & -2.5945 & -1.7134 \\
\hline
\end{tabular}

need to pay close attention to the sustainable development levels in their regions, instead of destroying the environment in exchange for economic development. The ICT has a significantly positive effect on ETI, indicating that information and communication technology development is one of the vital variables affecting ETI. Thus, local governments need to endeavor to increase Internet penetration rates and promote the application of information and communication technology and industry development. Meanwhile, human capital has a positive but nonsignificant effect on ETI, indicating that, during the sample period, it did not have a considerable impact on the growth of ETI.

5.2. Discussion. In general, OFDI does not have a reverse spillover effect on ETI, but the relationship does exhibit nonlinear characteristics. Due to the different levels of regional IPP, OFDI's role in promoting ETI follows both increasing and decreasing trends, and this is because IPP is an essential institutional environment variable. For host countries, accepting foreign investment not only promotes domestic economic growth but also needs to consider the security of core technologies to prevent core technologies from being imitated and weakening competitiveness case. In particular, the growth of the green economy has become a significant concern for all countries. As a prevariable of sustainable development, ETI can fundamentally promote healthy economic growth and make green technological progress the core technological capability of each country.
Therefore, international trade exchanges should pay more attention to protecting property rights for green technological advancement. Thus, OFDI's impact on ETI varies significantly based on IPP levels.

In low IPP areas, OFDI hurts ETI. In international trade cooperation, awareness of the IPP level of home country enterprises is too low, and host country companies may be reluctant to collaborate with home country companies on high technology and core innovations due to the risk of technology imitation. This is also the main reason why China has long been at the low end of the global value chain. Because of the low IPP levels in regions where home country enterprises are located, even home country enterprises that have obtained technological spillovers in competition with enterprises in host countries will be unwilling to cooperate with other enterprises in the area of technology. Simultaneously, ETI has high-input low-output characteristics and carries certain risks, which many companies cannot afford. Therefore, it is challenging to transform cutting-edge technologies and produce green economic benefits.

In the middle and high IPP range, OFDI has a significant positive impact on ETI. The main reason is that, on the one hand, a high level of IPP can reduce the risk of imitating the innovative products of enterprises that conduct foreign direct investment activities. This encourages multinational companies to introduce advanced foreign technologies into the country. By learning, absorbing, and reinnovating advanced foreign technologies, they have improved the technological innovation capabilities of multinational 
TABLE 5: Distribution of relative thresholds of IPP in 30 provinces of China.

\begin{tabular}{|c|c|c|c|c|}
\hline \multicolumn{3}{|c|}{$1.0616<\mathrm{IP} \leq 1.3551$} & \multicolumn{2}{|l|}{$\mathrm{IP}>1.3551$} \\
\hline & Region & Number & Region & Number \\
\hline 2009 & Tianjin, Liaoning, Zhejiang, Hainan, Chongqing, and Ningxia & 6 & Beijing, Shanghai, and Guangdong & 3 \\
\hline 2011 & $\begin{array}{c}\text { Liaoning, Zhejiang, Fujian, Guangdong, Chongqing, Ningxia, } \\
\text { and Xinjiang }\end{array}$ & 7 & Beijing, Shanghai, and Guangdong & 3 \\
\hline 2013 & $\begin{array}{c}\text { Liaoning, Jiangsu, Zhejiang, Fujian, Guangdong, Chongqing, } \\
\text { and Ningxia }\end{array}$ & 7 & Beijing, Tianjin, Shanghai, and Guangdong & 4 \\
\hline 2015 & $\begin{array}{c}\text { Tianjin, Liaoning, Zhejiang, Fujian, Guangdong, and } \\
\text { Chongqing }\end{array}$ & 6 & $\begin{array}{l}\text { Beijing, Tianjin, Shanghai, Chongqing, and } \\
\text { Guangdong }\end{array}$ & 5 \\
\hline 2017 & $\begin{array}{c}\text { Liaoning, Jiangsu, Zhejiang, Fujian, Guangdong, Chongqing, } \\
\text { and Ningxia }\end{array}$ & 7 & Beijing, Shanghai, Zhejiang, and Guangdong & 4 \\
\hline
\end{tabular}

Note. The eastern regions include Beijing, Tianjin, Hebei, Shanghai, Jiangsu, Zhejiang, Shandong, and Guangdong; the central areas include Anhui, Jiangxi, Henan, Hubei, and Hunan; the western areas include Chongqing, Sichuan, Guizhou, Shaanxi, and Gansu. The northeast region includes Heilongjiang and Liaoning; other regions were not included in the sample due to serious data missing.

companies and motivated other domestic companies to improve their techniques. This has promoted the green technology progress of the home country and promoted recognition of OFDI's reverse environmental technology spillover effect. On the other hand, strong IPP can protect the interests of innovators and enable them to obtain lasting benefits through international trade, thereby increasing innovation investment, accelerating research and the development of new technologies and products, and ultimately improving companies' technological innovation capabilities. Moreover, strong IPP helps expand international trade and enhance the quality of cooperation, deepen the opening up to the outside world, increase the global competitiveness of regional enterprises, and promote green technological progress in the home country. However, it is worth noting that, as the level of IPP continues to rise, the impact of OFDI on ETI weakens, and this is because excessively high levels of IPP may increase enterprises' innovation costs, discourage innovation enthusiasm in enterprises, and cause repeated innovation.

5.3. Time and Space Heterogeneity. Applying the dualthreshold model, in the following section, this paper analyzes the distribution of the relative threshold value of the intellectual property protection intensity in 30 regions of China from 2009 to 2017, as shown in Table 5.

During the sample period, the number of regions in the relatively optimal range of intellectual property protection intensity $(\mathrm{OFDI}(1.0616<\mathrm{IPP} \leq 1.3551))$ did not increase substantially, which confirms that China's intellectual property protection is generally at a relatively low level. The three provinces of Liaoning, Guangdong, and Chongqing have always been in the optimal intellectual property rights range. As a sizeable northeastern province, Liaoning has achieved remarkable results in transforming from traditional heavy industries to high-end manufacturing and service industries in recent years. The volume of foreign trade continues to grow, and the business environment continues to improve. In this process, Liaoning province has continuously innovated systems and mechanisms, strengthened organization and implementation, and achieved exact results in crucial areas such as the creation, protection, and application of intellectual property rights. As one of the crucial provinces in the eastern region, Guangdong province has continuously strengthened the construction of intellectual property rights while the economy has developed steadily. In 2018, a total of 2.396 million cases were completed for the first review, and the review period was significantly reduced within five months. The time limit for patent pledge registration and patent implementation license contract filing was reduced to 5 working days, and the province's electronic application rate reached over 98\%. Ningxia is a province in western China. Although its economic development level is relatively low, it has always attached importance to intellectual property protection. Ningxia has successively issued regulations such as the "Action Plan for the Implementation of the Intellectual Property Strategy in Ningxia Hui Autonomous Region (2015-2020)" and the "Thirteenth Five-Year Plan for Intellectual Property Protection and Use of Ningxia." Moreover, Ningxia has continuously promoted the creation and application of intellectual property rights by improving intellectual property transaction service mechanisms, implementing a project to strengthen intellectual property rights, and building both intellectual property-intensive areas and demonstration areas.

The provinces in the high intellectual property range (OFDI (IPP > 1.3551)) are all in eastern China. Beijing and Shanghai have always been in this range. These two provinces have healthy economic development, frequent trade exchanges, strong awareness of intellectual property protection, and a complete intellectual property protection system. As one of the municipalities directly under the Central Government, Tianjin has many ports and is an important city for China's foreign trade exchanges. In recent years, economic development and intellectual property protection levels have significantly improved. In 2018, on the occasion of the 18th World Intellectual Property Day, Beijing, Shanghai, and Tianjin officially launched the Intellectual Property Publicity Week, demonstrating that the governments of these three provinces attach great importance to the protection of intellectual property rights and that the public has a strong awareness of intellectual property rights protection. 
TABLE 6: Analysis of the contribution rate of OFDI to regional ETI capabilities.

\begin{tabular}{lccc}
\hline Region & OFDI (IPP $\leq 1.0616))$ & OFDI $(1.0616<$ IPP $\leq 1.3551)$ & OFDI(IPP $>1.3551)$ \\
\hline Coef. & -0.2945 & 1.5780 & 0.4832 \\
Contribution (\%) & -15.682 & 84.026 & 25.730 \\
\hline
\end{tabular}

TABLE 7: Model parameter estimation result.

\begin{tabular}{lcccccc}
\hline ETI & Coef. & Std. err & $\mathrm{t}$ & $P>|t|$ & $95 \%$ & Conf. interval \\
\hline City & 1.5116 & 0.3335 & 4.53 & 0.000 & 0.8539 & 2.1692 \\
Human & -0.0060 & 0.0195 & -0.31 & 0.761 & -0.0445 & 0.0326 \\
LCED & -0.0040 & 0.0016 & -2.41 & 0.017 & -0.0072 & -0.0007 \\
ICT & 0.1416 & 0.0286 & 4.95 & 0.000 & 0.0852 & 0.1980 \\
OFDI (IPP $\leq 1.061)$ & -0.3414 & 0.1564 & -2.18 & 0.030 & -0.6498 & -0.0329 \\
OFDI $(1.0616<$ IPP $\leq 1.3551)$ & 1.8478 & 0.1801 & 10.26 & 0.000 & 1.4926 & 2.2029 \\
OFDI (IPP $>1.3551)$ & 1.0969 & 0.3034 & 3.62 & 0.000 & 0.4987 & 1.6952 \\
Cons & -1.9740 & 0.2459 & -8.03 & 0.000 & -2.4589 & -1.4890 \\
\hline
\end{tabular}

5.4. Contribution Rate Analysis. Because the marginal effect elasticity coefficient can only reflect whether the independent variable has a significant effect on the dependent variable, it cannot reflect the relative contribution of the independent variable or the changes in the dependent variable. Therefore, based on the elasticity coefficient, this article calculates the contribution rate of OFDI to the technological innovation capabilities of the interprovincial environment.

The specific calculation method is as follows: first, the average OFDI value for the 30 provinces from 2009 to 2017 is calculated. The 2009 average is subtracted from the 2017 average, and then the average change in OFDI from 2009 to 2017 is calculated. Next, the average change in IPP from 2009 to 2017 is calculated in the same way. Then, the elasticity coefficient of OFDI is multiplied by the magnitude of its change to obtain the change value of the interprovincial ETI capacity caused by OFDI changes during the sample period. Finally, the obtained change value is divided by the change in IPP rights and multiplied by $100 \%$. The ratio obtained is OFDI's contribution rate to the change in ETI capacity.

As Table 6 shows, when IPP rights do not cross the threshold of 1.0616, OFDI's contribution rate to ETI capacity is $-15.682 \%$. In other words, regional ETI cannot be promoted through OFDI. When the IPP level is in the [1.0616, 1.3551] range, the OFDI's contribution rate to the ETI capacity of each province increases to $84.026 \%$. Finally, when the IPP level exceeds 1.3551 , OFDI contributes $25.73 \%$ to local ETI capacities. These findings regarding OFDI's contribution rate demonstrate an optimal IPP interval [1.0616, 1.3551] in which OFDI has a higher contribution rate to regional ETI capabilities.

5.5. Robustness Test. To test the robustness of the results, this paper uses Qi and Li [39] approach, adjusts the method of the research samples, deals with biases that may be caused by outliers, and conducts robustness tests. The specific method involves deleting the most extensive and smallest $1 \%, 5 \%$, and 10\% OFDI sample areas and 26 provinces and 24 provinces in China; the results are relatively consistent
(Table 7). That is, when the intensity of intellectual property protection is in the low threshold range, OFDI's reverse environmental technology innovation overflow is invalid. When the intensity of intellectual property protection is in the middle threshold range, OFDI's reverse environmental technology innovation spillover is most effective. Finally, when the intensity of intellectual property protection is in the high threshold range, OFDI's reverse environmental technology innovation spillover is significant but is limited. This is consistent with the above estimation results, indicating that the conclusion is robust. Due to space limitations, the threshold test results are only listed for 26 provinces in this article.

\section{Conclusions and Recommendations}

In recent years, technological advances have led to rapid economic and social development in various countries. Nevertheless, the methods used to achieve rapid economic development and growth have put enormous pressure on the ecological environment. As the problem of environmental pollution worsens, people's environmental awareness is continually increasing. Traditional technological innovation is mainly to meet people's needs for economic benefits. However, in addition to meeting economic development needs, technological innovation also needs to achieve environmental benefits. A country or region's ETI ability is to enhance its sustainability, the source of competitiveness. Based on the research perspective of economic globalization, this paper constructs a nonlinear panel regression model of IPP, OFDI, and ETI. It tests the hypotheses put forward in the previous article. This article draws the following conclusions.

First, considering the two dimensions of technological innovation (i.e., knowledge benefits and economic impacts), this paper uses the technological innovation capability per unit of energy consumption to calculate the regional environmental technology innovation level. Based on this, this paper uses the RAGA-PP model to evaluate and analyze the environmental technology innovation capabilities in 30 regions of China. The results show that, as a whole, China's 
environmental technology innovation level is increasing year by year. Still, the regional heterogeneity is very significant, manifesting in a downward gradient of "eastmiddle-west" similar to economic development. The eastern region has a relatively high level of environmental technology innovation, especially in developed cities such as Guangdong, Jiangsu, and Shanghai. The levels of environmental technology innovation in the central regions, such as Anhui and Hunan, lag behind the eastern region. Still, both show an increasing trend year by year. This indicates that the central region, which has been dominated by heavy industry, has achieved remarkable results in industrial transformation, increased awareness of environmental protection, and continuously improved clean production levels. The environmental technology innovation levels in the western and northeastern regions are relatively low, and there is more room for improvement. Although Chongqing is located in southwest China, it has a relatively high level of environmental technology innovation. It is worth noting that the two provinces of Liaoning and Heilongjiang have low environmental technology innovation capabilities and little progress. To improve the environmental technology innovation capabilities of these regions, their industrial structure needs to be adjusted urgently.

Second, based on the threshold model analysis method, this paper puts OFDI, IPP, and ETI in the same research framework and analyzes their complex nonlinear influence mechanisms. The results show that the influence of OFDI on ETI has nonlinear characteristics and there is a double threshold effect with IPP as the threshold. As IPP levels continue to cross the threshold, OFDI's effect on ETI changes from negative to positive. When IPP is in the middle protection intensity range, OFDI can significantly promote the improvement of ETI performance. Every $1 \%$ increase of OFDI can promote ETI growth by $1.578 \%$, the most significant improvement. However, when the IPP is in the high protection intensity range, although OFDI is conducive to the ETI progress, the coefficient of action becomes smaller, and the level of significance decreases. Thus, this paper's findings further validate the "optimal IPP interval" theory proposed by Park (2008).

Finally, the regional intellectual property protection that OFDI drives ETI progress has significant heterogeneity, and there are large differences in temporal and spatial distribution. According to the threshold level, the 30 regions can be divided into low intellectual property protection zone, medium intellectual property protection zone, and high intellectual property protection zone. In general, although the number of provinces in the optimal intellectual property protection zone has increased, the change is relatively limited. The majority of provinces are still in the low intellectual property protection zone. This is an extremely unfavorable situation for foreign direct investment in promoting environmental, technological innovation, and highquality economic development. Besides, the fact that most provinces in the western region have relatively low levels of intellectual property protection requires special attention.

The conclusions outlined above suggest that efforts to improve China's ETI capacity, enhance its level of sustainable development, and improve the status of its global value chain and global innovation chain will require work in the following areas.

On the one hand, as an emerging economy, OFDI is a vital technology spillover path. The Chinese government should further implement the "going out" strategy and encourage various domestic enterprises, especially private enterprises, to carry out the overseas direct investment. This will help domestic enterprises acquire external $\mathrm{R} \& \mathrm{D}$ elements and technical resources and actively raise domestic technical levels and overall industrial strength. In this process, as a useful supplement to the content of the "going out" strategy, policy-making agencies should pay close attention to the international situation and seek to improve investment policies continuously. At the same time, the government must conform to regional industrial structures when promoting the layout of foreign investment by enterprises. For example, the government should vigorously advocate for foreign investment in technology-intensive industries, encourage domestic high-tech enterprises to carry out foreign direct investment in technology-leading countries, and perform highquality follow-up work such as information consultation and intellectual property protection. Besides, when carrying out foreign direct investment activities, enterprises should pay attention to strengthening their abilities of absorbing advanced technologies and improving the efficiency of industrial upgrading.

On the other hand, intellectual property protection is an essential institutional factor that affects the reverse environmental technology spillover of foreign direct investment. Since China is still undergoing a period of economic transition, the institutional environment is not yet perfect; intellectual property protection levels in most regions cannot promote the reverse technology spillover of foreign direct investment. Therefore, strengthening intellectual property protection will help strengthen current reverse technology feedback. China must actively improve the existing intellectual property protection system, placing a particular emphasis on improving external intellectual property protection; it must also effectively implement intellectual property law to ensure its desired effect. Besides, the government must recognize the strength of intellectual property protection and build a flexible intellectual property protection system. China can flexibly adjust the level of intellectual property protection according to the actual situation, so that it can give full play to its role and promote the level of environmental technology innovation.

\section{Data Availability}

The data used in this article can be downloaded from the NBS website.

\section{Conflicts of Interest}

The author declares that there are no conflicts of interest. 


\section{Acknowledgments}

This study was supported by the Soft Science Project of Shandong Province (2019RKB01250) and Shandong Province Higher Education "Green Innovation Science and Technology Plan” Project (2020RWB003).

\section{References}

[1] C. Stoian, "Extending dunning's investment development path: the role of home country institutional determinants in explaining outward foreign direct investment," International Business Review, vol. 22, no. 3, pp. 615-637, 2013.

[2] F. Fan, H. Lian, and S. Wang, "Can regional collaborative innovation improve innovation efficiency? An empirical study of Chinese cities," Growth and Change, vol. 51, no. 1, pp. 440-463, 2020.

[3] D. Han, T. Li, S. Feng, and Z. Shi, "Application of threshold regression analysis to study the impact of clean energy development on China's carbon productivity," International Journal of Environmental Research and Public Health, vol. 17, no. 3, p. 1060, 2020.

[4] M. Li, "Human capital, R\&D input and OFDI's reverse technology spillovers," World Economy Study, vol. 10, pp. 69-75+89, 2010.

[5] W. B. Sha, "OFDI, reverse technology spillovers and domestic innovation abilities," World Economy Study, pp. 69-74+89, 2012.

[6] C.-L. Chang, S.-P. Chen, and M. McAleer, "Globalization and knowledge spillover: international direct investment, exports and patents," Economics of Innovation and New Technology, vol. 22, no. 4, pp. 329-352, 2013.

[7] J. J. Wu and Y. Qiu, "A research of the technological innovation effect through China's outward direct investment: from the perspective of the R\&D inputs and outputs," Modern Economic Science, vol. 35, pp. 75-80+127, 2013.

[8] G. Lee, "The effectiveness of international knowledge spillover channels," European Economic Review, vol. 50, 2005.

[9] J. Bitzer and M. Kerekes, "Does foreign direct investment transfer technology across borders? New evidence," Economics Letters, vol. 100358 pages, 2008.

[10] D. Herzer, "The long-run relationship between outward foreign direct investment and total factor productivity: evidence for developing countries," Journal of Development Studies, vol. 47, no. 5, pp. 767-785, 2011.

[11] Y. M. Xie, K. T. Zhou, and X. P. Wei, "The research on reverse spillover effects on China's innovation capability of outward foreign direct investment," Economic Survey, vol. 31, pp. 42-47, 2014.

[12] S. H. Li and J. P. Yu, "Foreign direct investment and enterprises' innovation efficiency," Journal of International Trade, pp. 28-38, 2016.

[13] W. M. Cohen and D. A. Levinthal, "Absorptive capacity: a new perspective on learning and innovation," Administrative Science Quarterly, vol. 35, 1990.

[14] D. X. Kan, "OFDI, marketing process and domestic enterprises' technology innovation-empirical study based on the provincial panel data of large and medium-sized industrial enterprises," R\&D Management, vol. 26, pp. 14-22, 2014.

[15] Z. H. Zhang, "Does environmental regulation affect OFDI reverse technology spillover," Statistics \& Information Forum, vol. 34, pp. 104-109, 2019.
[16] G. S. Eskeland and A. E. Harrison, "Moving to greener pastures: multinationals and the pollution-haven hypothesis," Journal of Development Economics, vol. 70, pp. 1-23, 1997.

[17] L. G. Yang and Y. N. Liu, “Can Japan's outwards FDI reduce its $\mathrm{CO}_{2}$ emissions?: A new thought on polluter haven hypothesis," Advanced Materials Research, vol. 807-809, pp. 830-834, 2013.

[18] Y. Y. Ouyang, X. F. Huang, and L. M. Zhong, "The impact of outward foreign direct investment on environmental pollution in home country: local and spatial spillover effects," China Industrial Economics, pp. 98-116, 2020.

[19] L. Zhou and C. X. Pang, "Home country environmental effects of China's foreign direct investment: based on the perspective of regional differences," China Population, Resources and Environment, vol. 23, pp. 131-139, 2013.

[20] Y. Han, Z. Li, F. Zhang, and C. Shen, "Environmental effects of bidirectional FDI in China," Resource Science, vol. 41, no. 11, pp. 2043-2058, 2019.

[21] H. Y. Liu and M. Li, "The home country effect research of China's OFDI on carbon emissions," Journal of Industrial Technological \& Economics, vol. 35, pp. 12-18, 2016.

[22] R. Wang and D. J. Zhu, "Outward foreign direct investment and sulfur dioxide emission in China," Economic Survey, vol. 35, pp. 48-55, 2018.

[23] P. Gammeltoft and B. Hobdari, "Emerging market multinationals, international knowledge flows and innovation," International Journal of Technology Management, vol. 74, pp. 1-22, 2018.

[24] R. Padilla-Perez and C. Gomes Nogueira, "Outward FDI from small developing economies," International Journal of Emerging Markets, vol. 11, no. 4, pp. 693-714, 2016.

[25] P. Piperopoulos, J. Wu, and C. Wang, "Outward FDI, location choices and innovation performance of emerging market enterprises," Research Policy, vol. 47, pp. 232-240, 2017.

[26] W. Li and Z. Y. Zhao, "Research on the reverse and dynamic industrial upgrading effect of China OFDI: based on the perspective of intellectual property protection," On Economic Problems, pp. 29-36, 2019.

[27] X. F. Han, W. F. Song, and R. J. Liu, "Home-country heterogeneous dynamic employment effect of China's OFDI," China Population, Resources and Environment, vol. 29, pp. 94-102, 2019.

[28] H. Fang, B. Peng, X. Wang, and S. Fang, "The effect of intellectual property rights protection in host economies on the sustainable development of China's outward foreign direct investment evidence from a cross-country sample," Sustainability, vol. 11, 2019.

[29] N. Papageorgiadis, Y. Xu, and C. Alexiou, "The effect of European intellectual property institutions on Chinese outward foreign direct investment," Management and Organization Review, vol. 15, no. 1, pp. 81-110, 2019.

[30] S. Ezzeddine and M. S. Hammami, "Nonlinear effects of intellectual property rights on technological innovation," Journal of Economic Integration, vol. 33, no. 2, pp. 1337-1362, 2018.

[31] F. Fan, D. Cao, and N. Ma, "Is improvement of innovation efficiency conducive to haze governance? Empirical evidence from 283 Chinese cities," International Journal of Environmental Research and Public Health, vol. 17, no. 17, p. 6095, 2020.

[32] F. Z. Wang, T. Jiang, and X. C. Guo, "Government quality, environmental regulation and green technological innovation of enterprises," Science Research Management, vol. 39, pp. 26-33, 2018. 
[33] B. E. Hansen, "Sample splitting and threshold estimation," Econometrica, vol. 68, no. 3, pp. 575-603, 2000.

[34] D. Yin and J. Q. Zhang, "Reverse technology spillover effects from China's OFDI: an empirical analysis from the perspective of absorptive capacity," Journal of International Trade, vol. 01, pp. 109-120, 2016.

[35] J. C. Ginarte and W. G. Park, "Determinants of patent rights: a cross-national study," Research Policy, vol. 26, no. 3, pp. 283-301, 1997.

[36] W. G. Park, "International patent protection: 1960-2005," Research Policy, vol. 37, no. 4, pp. 761-766, 2008.

[37] C. P. Wu and D. Tang, "Enforcement of intellectual property protection, technology innovation and corporate performance: evidence from Chinese listed companies," Economic Research Journal, vol. 51, pp. 125-139, 2016.

[38] C. M. Xu and X. G. Shan, "Constructing of the index system and verification for the intensity of intellectual property protection in China," Studies in Science, pp. 715-723, 2008.

[39] S. Z. Qi and Y. Li, "Threshold effects of renewable energy consumption on economic growth under energy transformation," China Population, Resources and Environment, vol. 28, pp. 19-27, 2018. 